\section{Commentary: Interests and Equal Moral Status}

\section{Kathy Squadrito Purdue University, Fort Wayne}

Professor DeGrazia argues that (1) we may give the interests of humans and animals equal consideration, (2) that this consideration does not entail that humans and animals have equal moral status, and (3) that humans do have higher moral status than animals. He concludes that the use of nonhuman animals in research is ethically justified. His position does not differ significantly from that of Frey. Both avoid the appearance of speciesism by providing a supposed objective criterion of moral worth. Both appeal to intuition to support such a criterion.

I find DeGrazia's position implausible for three reasons: first, it cannot be put into practice; second, intuitions differ and cannot be used as a ground for assuming that humans are more worthy than animals; and third, the plausibility of his view depends on accepting a framework that is generally destructive of life.

My comments will be restricted to two of his contentions; first, that differences in moral status appear with regard to the interest of freedom and second, that differences in moral status appear most vividly with respect to life. As he points out, this position is not uncommon. Singer claims that the rejection of speciesism does not imply that all lives are of equal worth. Most philosophers contend that human life is more valuable than animal life, and that some animal lives are more valuable than other animal lives. DeGrazia contends that captivity would generally do

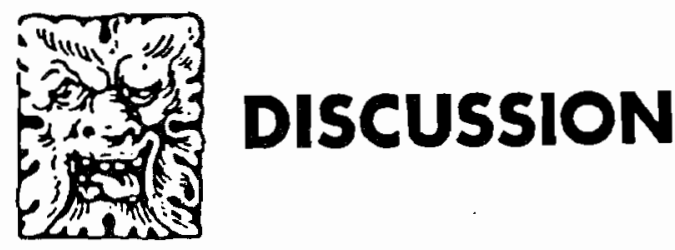

more violence to a human's plans than it would to the totality of things an animal would want to do. One should therefore prefer the use of animals over humans in freedom-restricting research. The death of a human, he says, thwarts more interests, and more important or central interests, than the death of an animal. He presents no evidence for these contentions, does not tell us what sort of animals humans are being compared to (except birds and dogs) and adds a value judgment that does not follow even if the premises that humans have more interests is true.

That human plans or interests are more important and central than animal interests is a statement that I am at a loss to comprehend. DeGrazia is careful to point out that the premise is "generally true," i.e., that some humans, e.g., "the very old, the retarded, do not always have plans that are so badly thwarted by captivity, while birds may be completely frustrated." I am not sure whether this type of theorizing involves empirical variables or exactly what DeGrazia would propose to do on the basis of empirical research into the thwarting of freedom. Do we construct a hierarchy of research animals based on the frustration of captivity? Do we select an elderly person or a retarded person rather than a bird? Do we select by how important we think a person's or animal's plans are? This may be non-speciesist, but I have never understood how philosophers can be comfortable with such a position.

DeGrazia asks the sceptic to consider all the things she wants to do in the next five days. I take it as far from obvious that humans, in general, do more various kinds of things than animals. More than half of the world's human population is so poor that they have very few plans other than seeking food, shelter, and medical care. They do not have freedom of mobility, freedom to choose what, or whether, they will eat. Most domestic dogs and cats have a "richer" life than most humans. Are we to conclude that these people should be used as experimental subjects rather than such animals? DeGrazia indicates that this type of objection may not be credible. By "humans," he says, "I mean normal humans." Although he does not carefully define "normal human," the sick, the starving, the elderly, the retarded, and the handicapped would probably not qualify as "normal." I find it highly objectionable to conclude that "normal" people have a higher moral status than those deemed not normal.

The life of domestic dogs is usually compared to the life of normal humans. Captivity, says DeGrazia, would 
generally do more violence "to a human's plans than it would to the totality of things the dog would want to do," as though the dog were not already captive. Since, in general, white males tend to do more various types of important things than blacks and women, we might as well conclude that they have a higher moral status.

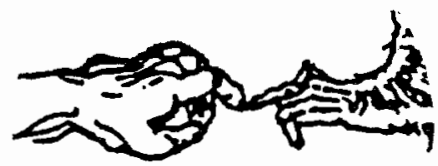

We may deem some interests to be more important than other interests, but I doubt that this is based on any objective criterion. To consider our own interests and opportunities more important and central in some cosmic sense is an elitist position that I cannot defend. To contend that normal people have a higher moral status than people who are not normal, to refer to such people as defective or as marginal cases, to contend that some animals have a higher moral status than some people, is, I think, the height of egotism. To suggest that the interests of a normal dolphin may be more important than those of an elderly, retarded human is an affront to human dignity. To contend that this is all very objective and based on detached reflection is to fool ourselves; philosophers give a sceptical eye to scientists who make such claims. That we are not dealing with pure objectivity is evidenced by the constant appeal to intuition.

DeGrazia points out that the intuition persists that the killing of a human is more destructive of something objectively valuable than the killing of an animal. What kind of intuition is this? My guess is that it is based on a long history of speciesism, based primarily on our desperate desire to be important and powerful in a universe that cares as much about us as it does a flea. The terms "higher moral status" and "higher value" are usually connected to some capitalist idea of productivity and usefulness to those in power. That our total obsession with hierarchies and ranking is destructive to all life has been demonstrated in numerous works.

Giving all sentient beings equal moral status would not solve the ethical dilemmas with regard to extreme cases. We are all worried about a philosophical framework which would throw us off a lifeboat. I would not throw a human being overboard in favor of a dog, not for DeGrazia's reasons, but simply because I selfishly value humans more. I do not believe that our choices in these situations are justified by any ethical theory.

\section{Response}

\section{David DeGrazia}

Let me briefly respond to Professor Squadrito's thoughtful commentary on my paper. Space precludes treating all of the objections, and I will honor none of the ad hominem remarks. To begin, I did not conclude that the use of animals in research is justified. The thesis was conditional and took this form: If research that harms animals is to be done at all, then such-and-such is, generally, a reason to prefer the use of animals over humans. For all I have asserted, Regan's view might be right, for it is compatible with the claim that normal humans and normal animals differ in moral status; indeed, his view implies this thesis with respect to lifeinterests. The truth is that I think a range of views are within reason and that each view within this range is compatible with the theses I advance, but I do not know which is correct.

Additionally, to be precise, I did not even argue that humans generally have greater moral status than animals, but rather that there is good reason to think so. This more modest claim is in keeping with my purposes, because my major objectives are (1) to distinguish the concepts of equal consideration and equal moral status and (2) to prove that the principle of equal consideration does not entail equality of moral status. These objectives are accomplished if it is shown that there is good reason to think there are differences in moral status while assuming the principle of equal consideration. I find it odd that Squadrito never comments on my two major theses.

However, I do, in fact, believe that there are differences in moral status. To deny this thesis is to accept fairly staggering implications, e.g., that there is no more reason, ethically, to save a human person in a "lifeboat situation" than to save a trout-that, given an

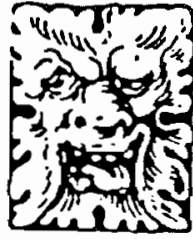
DISCUSSION 